\title{
What Happens to Modifiable Cardiovascular Risk Factors over Time in Type 2 Diabetes? Experience from a Developing Country under Standard of Care Conditions
}

\author{
Raya S. Zreik¹, Haytham I. Salti², Ibrahim S. Salti1', Roula Boukhalil1', Tamer Haddad1, Mona P. Nasrallah1* \\ ${ }^{1}$ Department of Internal Medicine, Faculty of Medicine, American University of Beirut Medical Center, Beirut, Lebanon \\ ${ }^{2}$ Department of Ophthalmology, Faculty of Medicine, American University of Beirut Medical Center, Beirut, Lebanon \\ Email: *mn36@aub.edu.lb
}

How to cite this paper: Zreik, R.S., Salti, H.I., Salti, I.S., Boukhalil, R., Haddad, T. and Nasrallah, M.P. (2016) What Happens to Modifiable Cardiovascular Risk Factors over Time in Type 2 Diabetes? Experience from a Developing Country under Standard of Care Conditions. Journal of Diabetes Mellitus, 6, 307-317.

http://dx.doi.org/10.4236/jdm.2016.64032

Received: October 31, 2016

Accepted: November 22, 2016

Published: November 25, 2016

Copyright $\odot 2016$ by authors and Scientific Research Publishing Inc. This work is licensed under the Creative Commons Attribution International License (CC BY 4.0).

http://creativecommons.org/licenses/by/4.0/

(c) (i) Open Access

\begin{abstract}
Introduction: The complications of diabetes mellitus are the main reason for the morbidity associated with this condition, its cost, and its effect on quality of life. We have previously reported on the high prevalence of complications on a cohort of diabetic subjects. In the current study, we inquire what happens to the risk factors associated with these complications over time. Methods: The study is a prospective observational report over a two-year period where patients presented to the outpatient clinic for their usual care and had laboratory tests, retinal exams, and clinical assessment. They were treated as per American Diabetes Association guidelines in the outpatient department of the American University of Beirut. Results: Out of 220 subjects, 200 completed the two-year evaluation. There was no change in metabolic indices such as HbA1C, BMI, or smoking rates. However, there was mild, but significant improvement in LDL-C levels and blood pressure control. In parallel, there was an increase in the use of statins and ARB/ACEI category. However, their use remained much lower than in the reported literature. The population fared worse than the National Health Assessment and Nutrition Examination Survey (NHANES) population in most diabetes quality of care measures. The predicted 10-year vascular risk was $19 \%$, similar to the calculated risk in a German population study. Conclusion: The lack of significant metabolic improvement points to a lack of effective lifestyle implementation measures, as well as to an under utilization of medical therapy. The approach to complications prevention needs to be more intense and multidisciplinary in nature in order to improve the patients' outcome.
\end{abstract}

\section{Keywords}

Cardiovascular Risk Factors, Diabetes Outpatient Clinic, Lebanon, T2DM 


\section{Introduction}

The need for multifactorial cardiovascular risk control in order to minimize type $2 \mathrm{di}$ abetes mellitus (T2DM) complications has long been emphasized and more recently confirmed by the STENO-2 extension study [1]. Furthermore, as a chronic condition, it is the duration of risk factor exposure which will determine more accurately the likelihood of complications.

As a developing country in the Middle-East North Africa (MENA) region, the prevalence of T2DM is moderately elevated in Lebanon [2]. We have previously shown that the risk factors and presence of complications were frequent in an adult diabetic population surveyed in a tertiary health care center [3]. It is not known what happens to these risk factors over time in the Lebanese population. One epidemiologic report from 4 countries of the MENA region suggests that risk factors such as smoking, obesity, and hypertension tend to worsen over a 15-year period [4]. However, these risk factors were assessed in a population study design, which would not include the same study subjects over time. The current study aims to assess the change over time in cardiovascular risk in the same cohort, under real life conditions. The primary objective of the study is to compare cardiovascular risk factors after a 2-year follow-up to baseline in adults with T2DM presenting to an outpatient clinic in a tertiary care center. The secondary objective is to compare these risk factors to other populations with T2DM, namely the National Health Assessment and Nutrition Examination Survey (NHANES) population [5].

\section{Patients and Methods}

\subsection{Procedures}

This is a prospective, longitudinal observational study. The recruitment process has been previously described with the report on the baseline cross-sectional data [3]. The study aimed to recruit at baseline 300 consecutive patients with T2DM who were presenting to the outpatient diabetes clinic at the American University of Beirut Medical Center (AUBMC) for their usual care. The study objective was to assess their T2DM control, risk factors, and complications. Exclusion criteria were age below 18 years, presence of type 1 diabetes mellitus or gestational diabetes, the inability to complete the initial assessment, or the two-year follow-up. The recruitment period started in August 2005 and ended in April 2007. The study was completed in May 2009.

The study was approved by the institutional review board of AUBMC and all patients gave their written informed consent at recruitment. Patients included in the study underwent an annual visit at baseline, one, and two years. Patients were called and reminded of the need for their annual visit where they were offered clinical assessment, laboratory measurements as outlined below, and a dilated eye exam. Patients' diabetes was managed as per usual care by the physician in the outpatient department and in accordance with the American Diabetes Association guidelines [6]. The study investigators did not interfere with the management of T2DM, but provided the results of 
each assessment visit to the patient and to the treating physician. Furthermore and per usual care, all patients were referred to the dietician for counseling at presentation. In addition, patients needing insulin were referred to the diabetes educator.

\subsection{Data Collection}

During each visit, medical history, anthropometric measures and physical examination were conducted. Blood pressure (BP) was obtained twice in the sitting position with a manual sphygmanometer at a 10-minute interval, and the average BP was recorded. Every patient completed a dilated fundus examination with the same retina specialist at each visit. In addition, they underwent fasting blood studies for $\mathrm{HbA1C}$, lipid profile, and creatinine. Spot urine was obtained for microalbumin to creatinine (ACR) ratio. At the two-year visit (visit 2), serum C-reactive protein (CRP) was also measured as an additional marker of cardiovascular risk.

\subsection{Definitions}

Cardiovascular risk indicators used during the study were: presence of obesity, smoking, or albuminuria; and the levels of HbA1C, lipid, CRP, and BP; and whether these were under control or not. Risk for cerebrovascular and cardiovascular disease was also computed with the variables used in the U.K. Prospective Diabetes Study (UKPDS) risk calculator namely age, gender, duration of diabetes, ethnicity, smoking status, presence of atrial fibrillation, HbA1C, systolic BP (SBP), total cholesterol, and HDL-cholesterol (HDL-C). All patients in the study were Caucasian and none of them had atrial fibrillation.

The same definitions were used as in the baseline cohort. Neuropathy was diagnosed by history or by evidence of decreased pressure sensation by monofilament test. Retinopathy was classified following the Early Treatment Diabetic Retinopathy Study (modified Airlie House) classification [7]. Nephropathy was defined according to the American Diabetes Association guidelines; [6] microalbuminuria: 30 - 299 mg/g Cr and macroalbuminuria: $>300 \mathrm{mg} / \mathrm{g}$ Cr. Macrovascular complications were provided by the patient history or by medical chart review; a patient was considered to have coronary artery disease (CAD) in case of a history of angina, myocardial infarction, coronary revascularization or documentation by angiography; peripheral vascular disease (PVD) in case of history of claudication, foot ulcer or peripheral revascularization, or if decreased pulses were noted on examination; cerebrovascular disease (CVD) in case of history of an event or radiological evidence of ischemia.

\subsection{Statistics}

Data were reported as means ( \pm standard deviation $[S D]$ ) or as absolute numbers and percentages. Data of the first and last visits were compared using two-sided tests: chisquared test for discrete variables and Student t-test for continuous variables. Additionally, comparison between the last follow-up and the 2000 NHANES population was used for certain Diabetes Quality of Care indicators (DQCI) using STATA [8] [9]. The 
NHANES survey provides data on a representative sample of the United States population. The subset of adults with T2DM had DQCI variables extracted, thus allowing the population findings to be compared to other populations with T2DM [10]. The 10-year coronary heart disease (CHD) risk was also calculated along with its $95 \%$ confidence interval (CI) using the UKPDS risk engine [11]. Statistical significance was set at the level of 5\%. Data were analyzed using SPSS, version 16.0 (SPSS Inc. Released 2007. SPSS for Windows, Version 16.0. Chicago, SPSS Inc.) and STATA.

\section{Results}

At baseline, 220 patients out of the 300 screened with T2DM were included in the analysis. Out of these, 200 completed their visit at two years. Twenty patients were lost to follow up, including three death reports: first death due to a complicated stroke, second death due to a complicated coronary artery bypass graft and the cause of the third death could not be collected from the family.

\subsection{General Characteristics}

The general characteristics of the patients at recruitment and at the last visit did not differ significantly (Table 1 ). At the last visit, the mean age of the patients was 59.0 $( \pm 10.0)$ years and $119 / 200(59.5 \%)$ were women. The mean duration of disease at the last follow-up was $11.4( \pm 6.6)$ years and $36.1 \%$ were current smokers.

\subsection{Metabolic Control}

The mean BMI was $31.4( \pm 6.9) \mathrm{kg} / \mathrm{m}^{2}$ and $56.2 \%$ of patients were obese (Table 2). Blood pressure control improved significantly at the last visit, with $66.0 \%$ of the cohort having a BP less than $140 / 90 \mathrm{mmHg}$ as compared to $55.2 \%$ at baseline $(p<0.05)$ (Table 2). Glycemic control of patients was stratified into good control (HbA1C less than 7\%), moderately poor control (HbA1C of 7\% - 9\%) and poor control (HbA1C above 9\%). Although the mean $\mathrm{HbAlc}$ remained relatively constant and equal to $8.4 \%( \pm 1.9)$, there was a redistribution of patients with only $21.5 \%$ of them being in the controlled range as compared to $30 \%$ at baseline.

The mean LDL-cholesterol (LDL-C) decreased significantly from $116( \pm 39) \mathrm{mg} / \mathrm{dL}$ to $104( \pm 35) \mathrm{mg} / \mathrm{dL},(p<0.001)$ and more patients in the controlled range with LDL-C

Table 1. Comparison of patients' general characteristics at baseline and year 2 .

\begin{tabular}{cccc}
\hline Characteristic & Unit & Baseline $\mathbf{n}=\mathbf{2 2 0 ^ { \mathrm { a } }}$ & Year 2 $\mathbf{n}=\mathbf{2 0 0}$ \\
\hline Mean age $( \pm$ SD) & Years & $57.7( \pm 10.6)$ & $59( \pm 10)$ \\
Women proportion & $\%$ (numbers) & $59(130 / 220)$ & $59.5(119 / 200)$ \\
Mean duration of disease $( \pm \mathrm{SD})$ & Years & $8.2( \pm 6.6)$ & $11.4( \pm 6.6)$ \\
Current smoker & $\%$ & $34.9(29.5 \%$ of females $)$ & $36.1(37.3 \%$ of females $)$ \\
\hline
\end{tabular}

a[3] Taleb, N., Salti, H., Al-Mokaddam, M., Merheb, M., Salti, I. and Nasrallah, M. (2008) Vascular complications of diabetes in Lebanon: Experience at the American University of Beirut. British Journal of Diabetes and Vascular Medicine, 8, 80-83. 
Table 2. Comparison of metabolic control between baseline and year 2 .

\begin{tabular}{|c|c|c|c|c|}
\hline Variable & Unit & Baseline & Year 2 & $p$-value \\
\hline Mean BMI & $\mathrm{Kg} / \mathrm{m}^{2}( \pm \mathrm{SD})$ & $30.3( \pm 5.5)$ & $31.4( \pm 6.9)$ & NS \\
\hline Obese (BMI $\geq 30$ ) & $\%$ & $\begin{array}{c}50.5 \\
\text { (57.9\% of females) }\end{array}$ & $\begin{array}{c}56.2 \\
\text { (59.8\% of females) }\end{array}$ & NS \\
\hline Mean BP & $\mathrm{mmHg}( \pm \mathrm{SD})$ & $132 / 79( \pm 20 / 11)$ & $130 / 78( \pm 16 / 11)$ & NS \\
\hline$\geq 140 / 90$ & $\%$ & 44.8 & 34 & $<0.05^{\mathrm{a}}$ \\
\hline HbAlc & $\%( \pm \mathrm{SD})$ & $8.5( \pm 2.4)$ & $8.4( \pm 1.9)$ & NS \\
\hline$<7$ & & 30 & 21.5 & \\
\hline $7-9$ & & 30.5 & 51 & \\
\hline$>9$ & & 39.5 & 27.5 & \\
\hline Mean LDL-C & $\mathrm{mg} / \mathrm{dL}( \pm \mathrm{SD})$ & $116( \pm 39)$ & $104( \pm 35)$ & $<0.001^{\mathrm{a}}$ \\
\hline$>130$ & & 33.6 & 26 & \\
\hline $100-130$ & $\%$ & 30.9 & 26.5 & \\
\hline$<100$ & & 35.5 & 47.5 & \\
\hline Mean HDL-C & $\mathrm{mg} / \mathrm{dL}( \pm \mathrm{SD})$ & $46.4( \pm 15)$ & $42.5( \pm 12)$ & $0.043^{\mathrm{a}}$ \\
\hline$>39$ & $\%$ men & 55.6 & 35.4 & \\
\hline$>50$ & $\%$ women & 47.7 & 30.3 & \\
\hline Mean TG & $\mathrm{mg} / \mathrm{dL}( \pm \mathrm{SD})$ & $2.2( \pm 1.8)$ & $1.9( \pm 1.5)$ & NS \\
\hline$<150$ & $\%$ & 42.3 & 52 & \\
\hline Mean CRP & $\mathrm{mg} / \mathrm{L}( \pm \mathrm{SD})$ & - & $7.9( \pm 10.0)$ & - \\
\hline Mean creatinine & $\mathrm{mg} / \mathrm{dl}( \pm \mathrm{SD})$ & $0.9( \pm 0.4)$ & $0.8( \pm 0.03)$ & NS \\
\hline
\end{tabular}

Microvascular Complications

\begin{abstract}
Mean albuminuria
\end{abstract}
Microalbuminuria

$30-299 \mathrm{mg} / \mathrm{g} \mathrm{Cr}$

$\geq 300 \mathrm{mg} / \mathrm{g} \mathrm{Cr}$

Retinopathy

NPDR

PDR

Neuropathy

Macrovascular Complications

$\begin{array}{lc}\text { CAD } & \% \\ \text { PVD } & \% \\ \text { CVA } & \%\end{array}$

\section{Medication use}

Hypolipidemic RX

Statin RX

ACE or ARB use $\mathrm{mg} / \mathrm{g} \mathrm{Cr}( \pm \mathrm{SD})$

$\%$

$\%$

$\%$

$\%$

$\%$

$\%$

$\%$
$158.2( \pm 366)$

46.3

30

12

31.1

23.6

7.5

39.9

19.3

18.3

4.1

39.1

31.7

46.8
$142.3( \pm 339.7) \quad$ NS

45.2

34

11.2

42.6

29.3

13.3

38.7

NS

$24.7 \quad$ NS

14.0 NS

$6.7 \quad$ NS

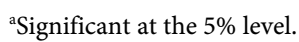


below $100 \mathrm{mg} / \mathrm{dL}$ were detected (47.5\% versus 35.5\%). However, HDL-cholesterol (HDL-C) levels also decreased from $46.4( \pm 12) \mathrm{mg} / \mathrm{dL}$ at the first visit to $42.5( \pm 12)$ $\mathrm{mg} / \mathrm{dL}$ at the last visit, $(p=0.043)$. Triglyceride levels did not change, and $52 \%$ had a triglyceride level of less than $150 \mathrm{mg} / \mathrm{dL}$. The CRP level available only during last visit was mildly elevated at $7.9( \pm 10 \mathrm{mg} / \mathrm{L})$. The CRP showed a weak positive linear correlation with BMI (coefficient $=0.206, p=0.03$ ), but did not show a correlation with HbAlc.

\subsection{Diabetes Complications}

The mean urine ACR did not significantly change from baseline $(158.2[ \pm 366.1] \mathrm{mg} / \mathrm{g}$ $\mathrm{Cr})$ and the final visit $(142.3[ \pm 339.7] \mathrm{mg} / \mathrm{g} \mathrm{Cr})$. Although the overall albuminuria frequency did not significantly increase, the incidence of albuminuria was $8 \%(16 / 200)$ over the study period. Also, 15 patients had albuminuria which reversed back to normoalbuminuria, and of whom 7 were on angiotensin-converting-enzyme inhibitor (ACEI) or angiotensin receptor blocker (ARB) (Table 3).

Retinopathy significantly increased from $31.1 \%$ to $42.6 \%(p<0.03)$; and this was accounted for by an increase in both nonproliferative and proliferative diabetic retinopathy (Table 2). As for the incidence, 18 (9\%) new cases developed diabetic retinopathy over the study period (Table 3). Among patients newly diagnosed with retinopathy, the mean duration of the disease was found to be 11.4 years with a mean HbA1c of 8.8\%.

No significant changes in the frequency of neuropathy, CAD, PVD and CVD were reported. However, the absolute rate of CAD was high affecting $24.7 \%$ of the cohort.

\subsection{Medication Use}

As compared to baseline, the cohort showed a significant increase in statin and ACEI/ ARB use; at the last visit, $49.0 \%$ versus $31.7 \%$ of the cohort was on statins ( $p=0.001$ ) and $59.0 \%$ versus $46.8 \%$ on ACEI/ARB, respectively $(p=0.012)$ (Table 2 ).

\subsection{Comparison to Other Populations}

Using some of the National Diabetes Quality Improvement Project indicators (NDQIP) [8] [9], our population fared poorly compared to the NHANES population [5] both at initiation and termination of the study for criteria such as HbA1C above 9\%, absence of microalbuminuria, and smoking rates. Surprisingly, LDL-C levels were under better

Table 3. Incidence of complications.

\begin{tabular}{lcccc}
\hline & & $\begin{array}{c}\text { New incidence } \\
\mathrm{n}(\%)\end{array}$ & $\begin{array}{c}\text { Reversal of disease } \\
\mathrm{n}(\%)^{\mathrm{a}}\end{array}$ & $\begin{array}{c}\text { Progression of disease } \\
\mathrm{n}(\%)\end{array}$ \\
\hline Nephropathy & Total & $16(8.0)$ & $15(7.5)$ & $7(3.5)^{\mathrm{b}}$ \\
& ACEI/ARB users & 10 & 7 & - \\
Retinopathy & & $18(9)$ & - & $5(2.5)$
\end{tabular}

${ }^{\mathrm{a}}$ Reversal of microalbuminuria or macroalbuminuria to normal ACR; ${ }^{\mathrm{b}}$ Progression from microalbuminuria to macroalbuminuria range. 
control at the second follow-up when compared to baseline or when compared to the NHANES population. Similarly, an improvement in BP was noted compared to baseline with no difference as compared to NHANES (Table 4).

When computing the 10 -year CHD risk, for patients $(n=141)$ with no prior CAD or cerebrovascular accident (CVA), with at least one measurement of HbAlc, cholesterol and SBP in visits at years 1 and 2, the average 10-year CHD risk was 18.5\% (95\% CI: $16.4 \% ; 20.7 \%)$. This rate is similar to the modelled risk in the Kooperative Gesundheitsforschung in der Region Augsburg (KORA) population study in Germany which calculated a risk of $19 \%$ from the 2007-2014 years [12].

\section{Discussion}

The current study compared in a longitudinal manner a cohort of patients with T2DM presenting for their usual care. It showed either similar risk or improvement in some of the cardiovascular risk factors, namely BP control and LDL-C level. Overall, the absolute values remain far from target recommendations and the cardiovascular risk remains high. Variables which are largely affected by lifestyle did not show improvement, namely HbA1C, BMI, HDL-C level, and smoking rates.

The improved BP and LDL-C control can be explained at least partially on the basis of increased use of statins and ACEI/ARB class. The relative "ease" in achieving target control with cholesterol and BP is largely medication-dependent, although lifestyle factors such as smoking and salt intake remain crucial for optimal control. Nonetheless, the rate of medication use remains very low and is lower in comparison to other observed cohorts namely STENO-2 [1], NHANES [5], and the population-based KORA cohort study [12]. Our study also reported a 10-year CHD risk similar to the 10-year CHD risk of $19 \%$ reported in Germany by Laxy et al. [12]. Although the outcome is not alarming in itself, the baseline existing CAD affecting nearly one quarter of the sample is an important indicator of the high morbidity in this population. Therefore, the risk for complications and the need for vigilance in prevention still stand.

Table 4. Comparison to NHANES population and between baseline and year 2.

\begin{tabular}{|c|c|c|c|c|c|}
\hline Indicator & $\begin{array}{c}\text { NHANES } \\
2000^{\prime} \text { s (\%) } \\
\mathrm{n}=750^{\mathrm{a}}\end{array}$ & $\begin{array}{c}\text { Cohort } \\
\text { Baseline (\%) } \\
\mathrm{n}=220^{\mathrm{b}}\end{array}$ & $\begin{array}{c}\text { Cohort } \\
\text { Year } 2(\%) \\
\text { n }=200\end{array}$ & $\begin{array}{c}P \text {-value } \\
\text { btw } \\
\text { BL' \& year 2 }\end{array}$ & $\begin{array}{c}P \text {-value between } \\
\text { NHANES \& year } 2\end{array}$ \\
\hline HbAlc > 9\% & 21 & 39.5 & 27.5 & NS & $0.05^{\mathrm{d}}$ \\
\hline LDL-C $<130 \mathrm{mg} / \mathrm{dl}$ & 64 & 66.4 & 74 & NS & $0.007^{\mathrm{d}}$ \\
\hline $\mathrm{BP}<140 / 90 \mathrm{mmHg}$ & 68 & 55.2 & 66.0 & $0.03^{\mathrm{d}}$ & NS \\
\hline $\begin{array}{c}\text { Absence of } \\
\text { microalbminuria }\end{array}$ & 67 & 53.7 & 54.8 & NS & $0.001^{\mathrm{d}}$ \\
\hline Current smokers & 19 & 34.9 & 36.1 & NS & $<0.001^{\mathrm{d}}$ \\
\hline
\end{tabular}

${ }^{a}[10]$ Saaddine, J., Cadwell, B., Gregg, E., Engelgau, M., Vinicor, F., Imperatore, G. and Narayan, K. (2006) Improvements in Diabetes Processes of Care and Intermediate Outcomes: United States, 1988-2002. Annals of Internal Medicine, 144, 465-474; ' $[3]$ Taleb, N., Salti, H., Al-Mokaddam, M., Merheb, M., Salti, I. and Nasrallah, M. (2008) Vascular complications of diabetes in Lebanon: Experience at the American University of Beirut. British Journal of Diabetes and Vascular Medicine, 8, 80-83; ${ }^{\mathrm{BL}}=$ Baseline; ${ }^{\mathrm{d}}$ Significant at the $5 \%$ level. 
Possible explanations for the lack of improvement in HbA1C, smoking and obesity rates are the difficulty in implementing significant lifestyle changes, especially in chronic disease. In support of this, The KORA study which is a national survey on the quality of diabetes care in Germany revealed similar trends in terms of poor patient self-management and physician-delivered care [12]. The difficulty in sustaining care, even in countries with socialized medicine, speaks for the nature of T2DM and its silent chronicity, which present a challenge to both the patient and the physician to sustain implementation of guidelines.

Studies which reflected a multidisciplinary and intensive approach in the treatment of T2DM have been typically more successful in the control of the condition. In the Diabetes Prevention Program (DPP), "the lifestyle intervention group" who received supervised intensive training in diet, physical activity of 150 minutes a week, and behavior modification showed a significant delay or prevention in development of diabetes, more than the group on metformin without intensive lifestyle modification [13]. The multidisciplinary approach success was well-illustrated in a retrospective within-group comparison study, in a clinic with previously poorly controlled subjects with T2DM. In this clinic, a cohort of diabetic patients was followed-up for at least one year by a Multidisciplinary Diabetes Care (MDC) team which consisted of endocrinologists, clinical pharmacists, clinical dieticians and certified diabetes nurse educators. When comparing the results to the pre-enrollment phase, considered as the "standard care phase", it was shown that the MDC approach was effective in improving glycemic and blood pressure control among diabetic patients [14]. The multidisciplinary approach in diabetes has been endorsed by the National Institute of Health [15].

Ideally, diabetes complications prevention should happen at the primary level, with preventing or delaying the condition itself the longest possible. However, given the size of the epidemic, the need for complications prevention remains imminent at the secondary and tertiary levels. The prevalence of T2DM is described to be around $16.7 \%$ using self-report, in a population study of Lebanese adults above 40 years of age [2]. In the current study, we have shown that the complications rate of these subjects is high, be it in microvascular or macrovascular rate, and the risk factors persist, and remain either equal or higher than other populations. We suggest that the reasons behind the high morbidity are possibly delay in diagnosis of T2DM, insufficient use of medical therapy (in a country where medical care is not socialized), and extremely poor lifestyle as reflected by high smoking and obesity rates. Measures to address all three are vitally needed. In support of the delay in diagnosis, it was estimated that about one quarter of subjects screened for T2DM in Beirut in 2005 did not know they had the condition [16]. One may argue that since study completion, new classes of hypoglycemic therapies have emerged such as glucagon like receptor agonists and sodium-glucose transport-2 inhibitors, with unprecedented demonstration of cardiovascular risk reduction [17] [18] [19]. However, the cost of such therapy in the population surveyed in our study would have been prohibitive and unlikely to have affected their use as they are not covered nor reimbursed by the Lebanese Ministry of Public Health dispensaries. 
Ultimately, our study strength is in data homogeneity as the information was collected by the same investigators, examined by the same ophthalmologist and run in the same laboratory. Also, this study is unique in Lebanon as it prospectively provides a follow-up on a cohort of patients with T2DM over a two-year period. In parallel, one limitation of the study is that our results cannot be likely generalized to the whole Lebanese population, as AUBMC remains a referral center, and the population attending the outpatient department is in general of lower socioeconomic status. Another limitation to the interpretation of results is that attitude and behavior regarding diabetes knowledge and lifestyle implementation was not formally assessed in this study [20]. It is therefore difficult to make any assertions as to the nature of lack of improving lifestyle measures. Finally, the duration of two years is too short to assess actual change in macrovascular outcomes, but reliable in assessing risk factor change.

\section{Conclusion}

This observational study evaluates the effectiveness of the current management of T2DM and reveals a high rate of suboptimal target delivery in about two-third of patients presenting to endocrine clinic. At baseline, there was a high rate of complications, and upon two-year follow-up there was persistence of complications risk factors. There is a call for an intense and multidisciplinary approach in awareness raising, effective lifestyle improvement measures and more medication accessibility to be implemented as a priority.

\section{Acknowledgements}

We are thankful for all patients who participated in the study.

\section{Conflict of Interest}

The authors declare that there is no conflict of interest regarding the publication of this paper.

\section{References}

[1] Gaede, P., Oellgaard, J., Carstensen, B., Rossing, P., Lund-Andersen, H., Parving, H.H. and Pedersen, O. (2016) Years of Life Gained by Multifactorial Intervention in Patients with Type 2 Diabetes Mellitus and Microalbuminuria: 21 Years Follow-Up on the Steno-2 Randomised Trial. Diabetologia, 59, 2298-2307. https://doi.org/10.1007/s00125-016-4065-6

[2] Costanian, C., Bennett, K., Hwalla, N., Assaad, S. and Sibai, A.M. (2014) Prevalence, Correlates and Management of Type 2 Diabetes Mellitus in Lebanon: Findings from a National Population-Based Study. Diabetes Research and Clinical Practice, 105, 408-415. https://doi.org/10.1016/j.diabres.2014.06.005

[3] Taleb, N., Salti, H.I., Al-Mokaddam, M., Merheb, M., Salti, I. and Nasrallah, M. (2008) Vascular Complications of Diabetes in Lebanon: Experience at the American University of Beirut. The British Journal of Diabetes and Vascular Disease, 8, 80-83. https://doi.org/10.1177/14746514080080020501

[4] Sozmen, K., et al. (2015) Cardiovascular Risk Factor Trends in the Eastern Mediterranean 
Region: Evidence from Four Countries Is Alarming. International Journal of Public Health, 60, S3-S11. https://doi.org/10.1007/s00038-014-0610-6

[5] Hyattsville, M.D. (2016) National Health and Nutrition Examination Survey. National Center for Health Statistics, NHANES 1999-2000 Data Files, U.S. Department of Health and Human Services, Centers for Disease Control and Prevention, National Center for Health Statistics. http://www.cdc.gov/nchs/about/major/nhanes/nhanes99_00.htm

[6] American Diabetes Association (2007) Standards of Medical Care in Diabetes. Diabetes Care, 30, S4-S41. https://doi.org/10.2337/dc07-S004

[7] (1991) Grading Diabetic Retinopathy from Stereoscopic Color Fundus Photographs-An Extension of the Modified Airlie House Classification. ETDRS Report Number 10. Early Treatment Diabetic Retinopathy Study Research Group. Ophthalmology, 98, 786-806. https://doi.org/10.1016/S0161-6420(13)38012-9

[8] Davidson, M. (1998) Diabetes Research and Diabetes Care: Where Do We Stand? Diabetes Care, 21, 2152-2160. https://doi.org/10.2337/diacare.21.12.2152

[9] Fleming, B., Greenfield, S. and Engelgau, M. (2001) The Diabetes Quality Improvement Project: Moving Science into Health Policy to Gain an Edge on the Diabetes Epidemic. Diabetes Care, 24, 1815-1820. https://doi.org/10.2337/diacare.24.10.1815

[10] Saaddine, J., Cadwell, B., Gregg, E., Engelgau, M., Vinicor, F., Imperatore, G. and Narayan, K. (2006) Improvements in Diabetes Processes of Care and Intermediate Outcomes: United States, 1988-2002. Annals of Internal Medicine, 144, 465-474. https://doi.org/10.7326/0003-4819-144-7-200604040-00005

[11] Stevens, R.J., Kothari, V., Adler, A.I. and Stratton, I.M., United Kingdom Prospective Diabetes Study (UKPDS) Group (2011) The UKPDS Risk Engine: A Model for the Risk of Coronary Heart Disease in Type II Diabetes (UKPDS 56). Clinical Science (London), 101, 671-679. https://doi.org/10.1042/cs1010671

[12] Laxy, M., Knoll, G., Schunk, M., Meisinger, C., Huth, C. and Holle, R. (2016) Quality of Diabetes Care in Germany Improved from 2000 to 2007 to 2014, But Improvements Diminished since 2007. Evidence from the Population-Based KORA Studies. PLoS ONE, 11, e0164704. https://doi.org/10.1371/journal.pone.0164704

[13] Knowler, W., Barrett-Connor, E., Fowler, S., Hamman, R., Lachin J., Walker, E. and Nathan, D., Diabetes Prevention Program Research Group (2002) Diabetes Prevention Program Research Group. Reduction in the Incidence of Type 2 Diabetes with Lifestyle Intervention or Metformin. The New England Journal of Medicine, 346, 393-403. https://doi.org/10.1056/NEJMoa012512

[14] Yokoyama, K., Cryar, A., Griffin, K., Godley, P. and Woodward, B. (2002) Cost-Effectiveness of a Multidisciplinary Diabetes Care Clinic. Drug Benefit Trends, 14, 113-114.

[15] (2011) Redesigning the Health Care Team: Diabetes Prevention and Lifelong Management. NIH Publication No. 11-7739 NDEP-37. National Diabetes Education Program, Bethesda.

[16] Hirbli, K.I., Aboujaoude, J.H., Ghorra, F.S. and Barakat-El-Khoury, W.M. (1990) Prevalence and Incidence of Diabetes Mellitus in Lebanon. Diabetes \& Metabolism, 16, 479-483.

[17] Zinman, B., et al. (2015) Empagliflozin, Cardiovascular Outcomes, and Mortality in Type 2 Diabetes. The New England Journal of Medicine, 373, 2117-2128. https://doi.org/10.1056/NEJMoa1504720

[18] Marso, S.P., et al. (2016) Liraglutide and Cardiovascular Outcomes in Type 2 Diabetes. The New England Journal of Medicine, 375, 311-322. https://doi.org/10.1056/NEJMoa1603827

[19] Marso, S.P., et al. (2016) Semaglutide and Cardiovascular Outcomes in Type 2 Diabetes. The New England Journal of Medicine, 375, 1834-1844. 
https://www.ncbi.nlm.nih.gov/pubmed

[20] Daly, J., Hartz, A., Xu, Y., Levy, B.T., James, P.A., Merchant, M.L. and Garrett, R.E. (2009) An Assessment of Attitudes, Behaviors, and Outcomes of Patients with Type 2 Diabetes. The Journal of the American Board of Family Medicine, 22, 280-290.

https://doi.org/10.3122/jabfm.2009.03.080114

Submit or recommend next manuscript to SCIRP and we will provide best service for you:

Accepting pre-submission inquiries through Email, Facebook, LinkedIn, Twitter, etc. A wide selection of journals (inclusive of 9 subjects, more than 200 journals)

Providing 24-hour high-quality service

User-friendly online submission system

Fair and swift peer-review system

Efficient typesetting and proofreading procedure

Display of the result of downloads and visits, as well as the number of cited articles

Maximum dissemination of your research work

Submit your manuscript at: http://papersubmission.scirp.org/

Or contact jdm@scirp.org 